\title{
Hippocampal Synaptic Modulation by the Phosphotyrosine Adapter Protein ShcC/N-Shc via Interaction with the NMDA Receptor
}

\author{
Yoshiaki Miyamoto, ${ }^{1}$ Ling Chen, ${ }^{2}$ Masahiro Sato, ${ }^{1}$ Masahiro Sokabe, ${ }^{2,3}$ Toshitaka Nabeshima, ${ }^{4}$ Tony Pawson, ${ }^{5}$ \\ Ryuichi Sakai, ${ }^{6}$ and Nozomu Mori ${ }^{1,7}$ \\ ${ }^{1}$ Department of Molecular Genetics, National Institute for Longevity Sciences, Oobu 474-8522, Japan, ${ }^{2}$ Cell Mechanosensing Project, International \\ Cooperative Research Project-Japan Science and Technology Agency, and Departments of ${ }^{3}$ Physiology and ${ }^{4}$ Neuropsychopharmacology and Hospital \\ Pharmacy, Nagoya University Graduate School of Medicine, Nagoya 466-8560, Japan, ${ }^{5}$ Department of Molecular and Medical Genetics, University of \\ Toronto, Toronto, Ontario M5S 1A8, Canada, ${ }^{6}$ Growth Factor Division, National Cancer Center Research Institute, Tokyo 104-0045, Japan, and \\ ${ }^{7}$ Department of Anatomy and Neurobiology, Nagasaki University School of Medicine, Nagasaki 852-8523, Japan
}

$\mathrm{N}-\mathrm{Shc}$ (neural Shc) (also ShcC), an adapter protein possessing two phosphotyrosine binding motifs [PTB (phosphotyrosine binding) and $\mathrm{SH} 2$ (Src homology 2) domains], is predominantly expressed in mature neurons of the CNS and transmits neurotrophin signals from the TrkB receptor to the Ras/mitogen-activated protein kinase (MAPK) pathway, leading to cellular growth, differentiation, or survival. Here, we demonstrate a novel role of $\mathrm{ShcC}$, the modulation of NMDA receptor function in the hippocampus, using $S h c C$ gene-deficient mice. In behavioral analyses such as the Morris water maze, contextual fear conditioning, and novel object recognition tasks, ShcC mutant mice exhibited superior ability in hippocampus-dependent spatial and nonspatial learning and memory. Consistent with this finding, electrophysiological analyses revealed that hippocampal long-term potentiation in ShcC mutant mice was significantly enhanced, with no alteration of presynaptic function, and the effect of an NMDA receptor antagonist on its expression in the mutant mice was notably attenuated. The tyrosine phosphorylation of NMDA receptor subunits NR2A and NR2B was also increased, suggesting that ShcC mutant mice have enhanced NMDA receptor function in the hippocampus. These results indicate that ShcC not only mediates TrkB-Ras/MAPK signaling but also is involved in the regulation of NMDA receptor function in the hippocampus via interaction with phosphotyrosine residues on the receptor subunits and serves as a modulator of hippocampal synaptic plasticity underlying learning and memory.

Key words: ShcC/N-Shc; phosphotyrosine adapter protein; learning and memory; long-term potentiation; hippocampus; NMDA receptor

\section{Introduction}

Long-term potentiation (LTP) in the hippocampus, a well characterized form of activity-dependent synaptic plasticity, serves as a major cellular mechanism of learning and memory (Bliss and Collingridge, 1993; Malenka and Nicoll, 1999). The NMDA and AMPA types of glutamate receptors (GluRs) play critical roles in the induction of hippocampal LTP (Tsien et al., 1996; Zamanillo et al., 1999). In addition to the primary importance of the glutamate receptors, it has been reported that neurotrophins, particularly brain-derived neurotrophic factor (BDNF), modulate the maintenance of hippocampal LTP through the activation of TrkB

Received March 3, 2004; revised Dec. 30, 2004; accepted Jan. 3, 2005.

The initial part of this work was supported by the program "Protecting the Brain" of the Core Research for Evolutional Science and Technology-Japan Science and Technology Agency, and later, in part, by a Virtual Research Institute of Aging fund of Nippon Boehringer Ingelheim, the Uehara Memorial Research Fund, Funds for Comprehensive Research on Aging and Health from Ministry of Health, Labor, and Welfare, and grants-in-aid from the Ministry of Education, Culture, Sports, Science, and Technology of Japan. We thank Dr. T. Nakamura for valuable advice and I. Nakano and Y. Kadokawa for technical assistance and laboratory maintenance.

Correspondence should be addressed to Dr. Nozomu Mori, Department of Anatomy and Neurobiology, Nagasaki University School of Medicine, 1-12-4 Sakamoto, Nagasaki 852-8523, Japan. E-mail: morinosm@net.nagasaki-u.ac.jp.

D01:10.1523/JNEUROSCI.3030-04.2005

Copyright $\odot 2005$ Society for Neuroscience $\quad 0270-6474 / 05 / 251826-10 \$ 15.00 / 0$ receptor tyrosine kinases (Poo, 2001; Lu, 2003). Also, a variety of intracellular signaling cascades, including the Ras/mitogenactivated protein kinase (MAPK) pathway, are reported to influence LTP formation (Ohno et al., 2001; Silva, 2003).

The BDNF-activated TrkB receptors recruit various adapter proteins such as Shc, Frs-2, and phospholipase-C $\gamma$ (PLC $\gamma)$. The adapter proteins are tyrosine phosphorylated by the activated TrkB receptors and determine the flow of downstream intracellular signaling cascades to cellular growth, differentiation, or survival. Binding of Shc or Frs-2 leads to the activation of Ras/MAPK and PI3K (phosphoinositide-3 kinase)/Akt pathways, whereas binding of PLC $\gamma$ stimulates the release of intracellular $\mathrm{Ca}^{2+}$ via inositol 1,4,5-trisphosphate (IP3) and thereby activates the $\mathrm{Ca}^{2+}$-calmodulin-dependent kinase IV (CaMKIV) pathway (Kaplan and Miller, 2000; Patapoutian and Reichardt, 2001). Therefore, it is hypothesized that TrkB-Ras/MAPK signaling plays a role in the hippocampal LTP underlying learning and memory (Adams and Sweatt, 2002; Ying et al., 2002).

The Shc family consists of ShcA/Shc (p66, p52, and p46 isoforms), ShcB/Sck (p68), and ShcC/neural Shc (N-Shc) (p69 and p55), and possesses two modular regions that bind to phosphorylated tyrosine-containing peptide motifs: a PTB (phosphoty- 
rosine binding) domain and an SH2 (Src homology 2) domain. All of the Shc family members serve to link a number of receptor tyrosine kinases with multiple intracellular signaling cascades. ShcA is widely expressed in most tissues, whereas both ShcB and ShcC are predominantly expressed in the nervous system (Cattaneo and Pelicci, 1998; Ravichandran, 2001). The brain-enriched ShcC would be in a good position to modulate the hippocampal LTP via regulation of TrkB-Ras/MAPK signaling, because it has been implicated in the BDNF-TrkB signaling toward the Ras/ MAPK pathway in cultured cells (Nakamura et al., 1998; Liu and Meakin, 2002).

Recent studies revealed that the so-called "Shc site" of the TrkB receptor $\left(\mathrm{Tyr}^{515}\right)$ was not relevant to the hippocampal LTP, because mice with a targeted point mutation of the TrkB-Shc site showed apparently no significant change in LTP formation (Korte et al., 2000; Minichiello et al., 2002). These findings are in contrast to the aforementioned hypothesis pointing to a role for TrkB-Ras/MAPK signaling in the hippocampal LTP. Accordingly, in the present study, we attempted to clarify whether the phosphotyrosine adapter protein ShcC, which binds the TrkBShc site leading to the Ras/MAPK pathway, is involved in hippocampal functions, using $S h c C$ gene-deficient mice. Based on the results presented herein, we propose a novel role for ShcC in hippocampal synaptic plasticity, as evidenced by the enhancement of hippocampal LTP and hippocampus-dependent learning and memory in ShcC mutant mice.

\section{Materials and Methods}

Animals. Mice lacking ShcC were generated by Sakai et al. (2000). The homozygous mutant mice ( $-1-; 3$ months of age) and the littermate 2 wild-type mice $(+/+; 3$ months of age) were obtained by crossing F2 heterozygous mutant mice $(+/-)$. The genotypes of mice were determined by Southern blot analyses of tail DNA. C57BL/6 mice (Nihon SLC, Hamamatsu, Japan) were used for biochemical analyses of the Shc family members. The mice were housed in plastic cages and were kept in a regulated environment $\left(24 \pm 1^{\circ} \mathrm{C} ; 50 \pm 5 \%\right.$ humidity), with a $12 \mathrm{~h}$ light/dark cycle (lights on at 9:00 A.M.). Food and tap water were available ad libitum. All of the experiments were performed in accordance with the Guidelines for Animal Experiments of the Nagoya University School of Medicine. The procedures involving animals and their care were conducted in conformity with the international guidelines Principles of Laboratory Animal Care (National Institutes of Health publication 85-23, revised 1985).

Plasmids and antibodies. Plasmids encoding cDNAs of mouse p52ShcA, p68-ShcB, and p55-ShcC were as described previously (Kojima et al., 2001) and were epitope-tagged with $\mathrm{T} 7$ at the $\mathrm{N}$ terminus. Antibodies against ShcA (catalog \#S68020) and ShcC (S55720) were obtained from Transduction Laboratories (San Diego, CA). Antibody against ShcB was prepared as described previously (Sakai et al., 2000). Anti-phosphotyrosine antibody (catalog \#05-321) was purchased from Upstate Biotechnology (Charlottesville, VA). Antibodies against NR1 (catalog \#sc-9058), NR2A (catalog \#sc9056), NR2B (catalog \#sc-9057), postsynaptic density 95 (PSD95) (catalog \#sc-6926), Src (catalog \#sc-5266), Fyn (catalog \#sc-434), and the Src family (catalog \#sc-18) were from Santa Cruz Biotechnology (Santa Cruz, CA). Anti-phospho-Src family (Tyr ${ }^{418}$ ) antibody (catalog \#44-660) was purchased from Biosource (Camarillo, CA).

Northern blot analysis. Total RNAs were isolated using TRIzol reagents (Invitrogen, Carlsbad, CA). Isolated total RNAs $(20 \mu \mathrm{g})$ were electrophoresed on a formalin/agarose gel and blotted onto a positively charged nylon membrane. Specific cDNA probes for the Shc family members were made by Megaprime DNA labeling systems and $\left[\alpha-{ }^{32} \mathrm{P}\right] \mathrm{dCTP}(\mathrm{Am}-$ ersham Biosciences, Piscataway, NJ) and purified with NucTrap Probe Purification Columns (Stratagene, La Jolla, CA). Membranes were hybridized with the ${ }^{32} \mathrm{P}$-labeled cDNA probes as described previously (Nakamura et al., 1998).

In situ hybridization analysis. Mouse brain sections (15 $\mu \mathrm{m})$ were cut on a cryostat, thaw-mounted on poly-L-lysine-coated slides, and stored at $-80^{\circ} \mathrm{C}$ until use. The frozen brain sections were brought to room temperature and air-dried. The sections were postfixed with $4 \%$ paraformaldehyde in $0.1 \mathrm{~m}$ phosphate buffer, acetylated with $0.25 \%$ acetic anhydride in $0.1 \mathrm{M}$ triethanolamine, and dehydrated through an ascending series of ethanol concentrations. To prepare antisense and sense cRNA probes, the plasmids encoding cDNA of ShcA, ShcB, or ShcC were linearized by cutting at a single site (antisense, EcoRI; sense, HindIII). In vitro transcription was performed using RNA polymerase (antisense, T7 RNA polymerase; sense, SP6 RNA polymerase) and $\left[\alpha^{-35}\right.$ S UTP (ICN Biomedicals, Costa Mesa, CA). In situ hybridization with the ${ }^{35} \mathrm{~S}$-labeled cRNA probes was performed as described previously (Nakamura et al., 1998). The sections were counterstained with thionine and dehydrated. The images were captured by the HC-2000 video camera system (Fuji Photo Film, Tokyo, Japan) and reconstructed using computer software.

Western blot analysis and immunoprecipitation assay. Mouse brains were homogenized in a lysis buffer [50 mM Tris-HCl, pH 7.5, $150 \mathrm{~mm}$ $\mathrm{NaCl}, 5 \mathrm{~mm}$ EDTA, $10 \mathrm{~mm} \mathrm{NaF}, 1 \mathrm{~mm}$ sodium orthovanadate, 1\% Triton $\mathrm{X}-100,0.5 \%$ sodium deoxycholate, $1 \mathrm{~mm}$ phenylmethylsulfonyl fluoride, and protease inhibitor mixture (Complete; Roche, Mannheim, Germany)] or a modified lysis buffer containing $0.1 \%$ SDS for immunoprecipitation assays. For Western blot analysis, total proteins $(10 \mu \mathrm{g})$ were separated by SDS-PAGE and blotted onto a polyvinylidene difluoride (PVDF) membrane. For immunoprecipitation assays, total proteins $(500$ $\mu \mathrm{g})$ were incubated with an appropriate antibody and then protein G-Sepharose was added and further incubated. The immunoprecipitates were recovered by centrifugation and resuspended in a sample buffer. The samples $(10 \mu \mathrm{l})$ were separated by electrophoresis and blotted onto a PVDF membrane. The membranes were incubated with primary antibodies, and proteins were detected by HRP-conjugated secondary antibodies using the ECL detection kit (Amersham Biosciences).

Histological analysis. Mouse brains were perfused with $4 \%$ paraformaldehyde in PBS and removed. Sections $(15 \mu \mathrm{m})$ were cut, mounted on slides, and stored at $-80^{\circ} \mathrm{C}$ until use. Nissl staining was done according to standard procedures. The images were captured with an HC-2000 video camera system. For immunochemical staining, the sections were permeabilized with $0.2 \%$ Triton X-100, blocked with $3 \%$ BSA, and incubated with antibody against microtubule-associated protein 2 (MAP2) (catalog \#M1406; Sigma, St. Louis, MO). To detect specific signals for MAP2, the sections were incubated with Alexa Fluor 488-conjugated secondary antibody (catalog \#A-11029; Molecular Probes, Eugene, OR). Fluorescence images were obtained with the confocal imaging system Micro Radiance (Bio-Rad Laboratories, Hercules, CA).

Behavioral analysis. To measure locomotor activity, a mouse was placed in a transparent acrylic cage with a black Plexiglas floor $(45 \times$ $26 \times 40 \mathrm{~cm}$ ), and locomotion and rearing were measured for $60 \mathrm{~min}$ using infrared counters (Scanet SV-10; Toyo Sangyo, Toyama, Japan).

To measure nociceptive responses to electric footshock, a mouse was placed in a transparent Plexiglas cage with a grid floor for footshock $(25 \times 30 \times 11 \mathrm{~cm})$ and an ascending footshock series $(0.01,0.02,0.03$, $0.04,0.05,0.06,0.08,0.10,0.13,0.16,0.20,0.25,0.30,0.40,0.50$, and 0.60 $\mathrm{mA}$ for $0.5 \mathrm{~s} ; 30 \mathrm{~s}$ interval) was delivered through an electric shock generator (NS-SG01; Neuroscience, Tokyo, Japan). The electric current needed to elicit first flinching, vocalizing, or jumping behavior was recorded as the footshock threshold.

For the Morris water maze task, a pool $(120 \mathrm{~cm}$ in diameter) was prepared with white plastic, and the water temperature was maintained at $20^{\circ} \mathrm{C}$. Swimming paths were analyzed by a computer system with a video camera (AXIS-90 Target/2; Neuroscience). In the hidden-platform test, the platform $(7 \mathrm{~cm}$ in diameter) was submerged $1 \mathrm{~cm}$ below the water surface. Mice did not swim in the pool before training. Three starting positions were used pseudorandomly, and each mouse was trained with three trials per day for $6 \mathrm{~d}$. After reaching the platform, the mouse was allowed to remain on it for $30 \mathrm{~s}$. If the mouse did not find the platform within $60 \mathrm{~s}$, the trial was terminated and the animal was put on the platform for $30 \mathrm{~s}$. In the platform transfer test, the mouse swam for $60 \mathrm{~s}$ in the pool without the platform. In the visible-platform test, the black platform was located $1 \mathrm{~cm}$ above the water surface.

For the fear conditioning task, a mouse was placed in a training cage 
$(25 \times 30 \times 11 \mathrm{~cm})$, which consisted of transparent Plexiglas with a grid floor for footshock, and the freezing response as the immobility time was measured for $2 \mathrm{~min}$ in the absence of sound and footshock (preconditioning) using Scanet SV-10AQ (Toyo Sangyo), which can measure automatically the immobility time by digital counters with infrared sensors. In the conditioning, the mouse was again placed in the cage, and the pretrial time of $2 \mathrm{~min}$ was followed by a $15 \mathrm{~s}$ tone stimulus $(80 \mathrm{~dB})$. During the last $5 \mathrm{~s}$ of the tone stimulus, a footshock of $0.8 \mathrm{~mA}$ was delivered through a shock generator (NS-SG01; Neuroscience). This procedure was repeated four times with $15 \mathrm{~s}$ intervals. In the pseudoconditioning, the mouse was exposed to the conditioning without footshock. For the contextual test $24 \mathrm{~h}$ after the conditioning, the mouse was placed back in the same cage in the absence of sound and footshock. For the cued test $24 \mathrm{~h}$ after the conditioning, the mouse was placed in a novel cage $(45 \times$ $26 \times 40 \mathrm{~cm}$ ), which was made of a transparent acrylic cage with a black Plexiglas floor, in the presence of a continuous tone stimulus.

For the novel object recognition task, a mouse was habituated to a black plastic cage $(30 \times 30 \times 50 \mathrm{~cm})$ for $3 \mathrm{~d}$. In the training, two novel objects were placed in the cage, and the mouse was allowed to explore freely for $5 \mathrm{~min}$. Time spent exploring each object was recorded manually. In retentions 2 or $24 \mathrm{~h}$ after the training, the mouse was placed back in the same cage, in which one of the familiar objects used in the training was replaced by a novel object, and allowed to explore for $5 \mathrm{~min}$. Exploratory preference, a ratio of time spent exploring any one of the two objects (training) or the novel one (retention) over the total time spent exploring both objects, was used to measure recognition memory.

Electrophysiological analysis. Mouse brains were removed and kept in artificial CSF (ACSF) (in mm: $128 \mathrm{NaCl}, 1.7 \mathrm{KCl}, 26 \mathrm{NaHCO}_{3}, 1.2$ $\mathrm{KH}_{2} \mathrm{PO}_{4}, 2.4 \mathrm{CaCl}_{2}, 1.3 \mathrm{MgSO}_{4}$, and 10 glucose). ACSF was saturated with a mixture of $95 \% \mathrm{O}_{2} / 5 \% \mathrm{CO}_{2}$. Slices of the hippocampus $(350 \mu \mathrm{m})$ were prepared using a microslicer (DTK-1500; Dosaka EM, Kyoto, Japan) and placed for $1 \mathrm{~h}$ in an incubation chamber filled with ACSF. The slices were stained with a voltage-sensitive dye, RH $482(0.1 \mathrm{mg} / \mathrm{ml}$; Nippon Kanko-Shikiso Kenkyusho, Okayama, Japan). The stained slices were transferred to a recording chamber mounted on an inverted microscope (IMT-2; Olympus, Tokyo, Japan). The recording chamber was continuously perfused with ACSF. The optical recording system (HR Deltaron 1700; Fuji Photo Film) consists of an area sensor with $128 \times 128$ photodiodes and a data-processing unit. Each photodiode receives optical signals from a $25 \times 25 \mu \mathrm{m}$ sample area, thus creating a $3.3 \times 3.3 \mathrm{~mm}$ recording field. For optical recordings, an ACSF-filled glass electrode was placed in the hippocampal CA3 area. Schaffer collateral afferents were then stimulated with $300 \mu \mathrm{A} / 200 \mu$ s pulses, and a test stimulus was delivered at $0.06 \mathrm{~Hz}$ by a stimulator (SEN-3301; Nihon Kohden, Tokyo, Japan). In each trial, background signals were recorded for $10 \mathrm{~ms}$ before the electrical stimulus and stored as a reference image. Images after the stimulus were recorded at $0.6 \mathrm{~ms} /$ frame, and the difference signals from the reference image were digitized into 8 bit signals. The digitized signals were then amplified 400 times. To improve the signal-to-noise ratio, 16 trial images were averaged into a single image. A total of 150 sequential images, corresponding to a $\sim 90 \mathrm{~ms}$ recording time, were collected from one experiment. The level of neuronal activities was indicated with pseudocolor ( 256 colors). To analyze the time course of activities in a given sample area, data from each pixel were stored, retrieved, and plotted as a function of time using Origin 5.0 (OriginLab, Northampton, MA).

In vitro kinase assay. Immunoprecipitates from the hippocampus were suspended in Src kinase reaction buffer (in mm: 100 Tris-HCl, pH 7.5, $125 \mathrm{MgCl}_{2}, 25 \mathrm{MnCl}_{2}$, 2 EGTA, 0.2 sodium orthovanadate, and 2 dithio- threitol). The kinase assay was performed using a Src kinase kit (catalog \#17-131; Upstate Biotechnology).

Pharmacological treatment of tissue slices. The hippocampi were quickly dissected and sliced in two directions at a thickness of $350 \mu \mathrm{m}$ using a McIlwain tissue chopper (Mickle Laboratory Engineering, Gomshall, $\mathrm{UK})$. The hippocampal slices were incubated at $37^{\circ} \mathrm{C}$ for $1 \mathrm{~h}$ in the netwell chamber (Corning, Corning, NY) filled with ACSF, which was continuously saturated with a mixture of $95 \% \mathrm{O}_{2} / 5 \% \mathrm{CO}_{2}$, and then exposed to ACSF in the presence of glutamate $(100 \mu \mathrm{M})$, glycine $(10 \mu \mathrm{M})$, and spermidine ( $1 \mathrm{~mm}$ ) for $5 \mathrm{~min}$. After a wash in ice-cold ACSF, the slices were homogenized in the modified lysis buffer.

Statistical analysis. All of the data were expressed as mean \pm SEM. Statistical differences between the mutant mice and the wild-type mice were determined with Student's $t$ comparison test. In the analysis of the visible or hidden test in the Morris water maze test, statistical differences were determined by an ANOVA with repeated measures. In the analysis of the transfer test in the Morris water maze, fear conditioning, and novel object recognition tasks, statistical differences among values for individual groups were determined by ANOVA, followed by the StudentNewman-Keuls multiple comparisons test when $F$ ratios were significant $(p<0.05)$.

\section{Results}

ShcC/N-Shc, a major phosphotyrosine adapter protein in the mature hippocampus

The gene expression of Shc-related phosphotyrosine adapter proteins was under dynamic regulation during the mammalian brain development (Fig. 1A,B). The expression level of ShcA, both the mRNA and protein, decreased during perinatal development and almost disappeared by 10 weeks of age. In contrast, that of ShcC increased gradually during postnatal development, with a peak at approximately postnatal day 7 (P7) to P14. However, ShcB mRNA levels remained low and invariable at all of the developmental stages, whereas its protein levels existed relatively high at P7 and P14. In situ hybridization analysis of young adults at 10 


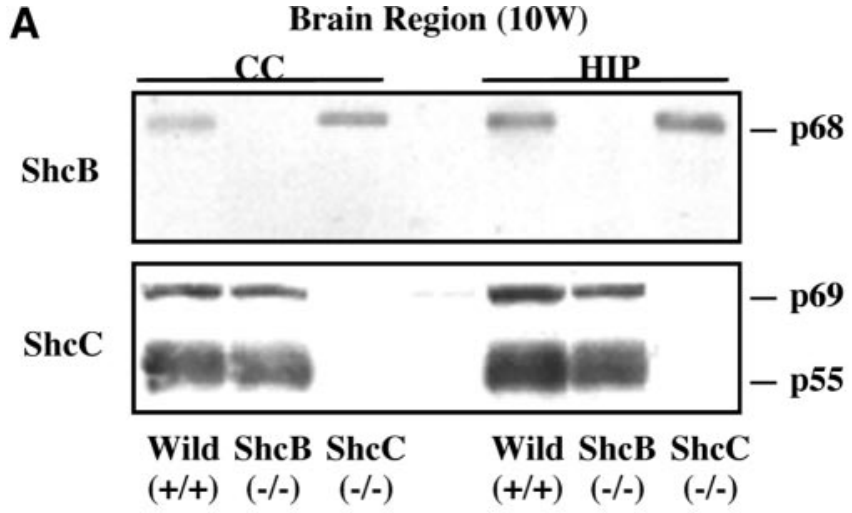

B Nissl Staining - HIP
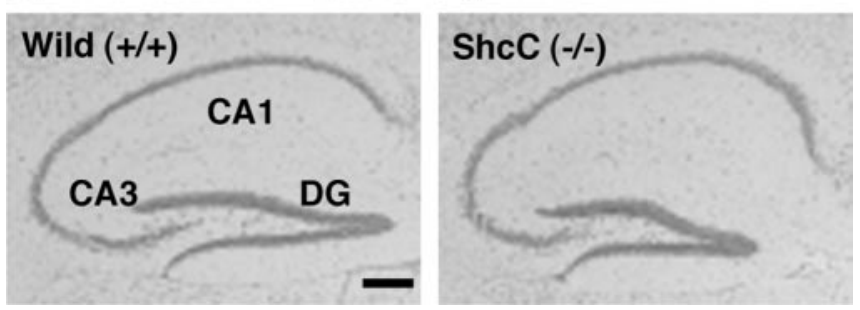

Figure 2. Hippocampal morphology in ShcC mutant mice. A, Protein expression of ShcB and ShcC in ShcC mutant mice [10 weeks of age (10W)]. Protein extracts from the cerebral cortex (CC) and hippocampus (HIP) of ShcB and ShcC mutant mice were examined by Western blot analysis. $\boldsymbol{B}$, Nissl staining in the hippocampus of ShcC mutant mice (10W). DG, Dentate gyrus. Scale bar, $200 \mu \mathrm{m}$.

weeks of age revealed that ShcC mRNA was highly expressed in the cerebral cortex, hippocampus, and thalamus (Fig. 1C). In contrast, the expression of ShcB mRNA was rather ubiquitous (Fig. 1C). The regional expression of ShcC protein correlated with the mRNA data, whereas that of ShcB protein was different from mRNA and showed some deviations (i.e., a few high expressions in the hippocampus, thalamus, and midbrain) (Fig. 1D). The expression of ShcA was negligible in the various regions of the brain at 10 weeks of age (data not shown). These findings indicate that ShcC is the primary phosphotyrosine adapter protein among the Shc family members in the hippocampus of adult animals.

\section{Histological appearance of hippocampal neurons in ShcC mutant mice}

ShcC mutant mice exhibited a complete loss of ShcC protein, but the expression of $\mathrm{ShcB}$ was unaffected in most regions of the brain at 10 weeks of age (Fig. $2 \mathrm{~A}$, cerebral cortex and hippocampus). Neuroanatomically, the hippocampus of ShcC mutant mice revealed no gross structural abnormalities on Nissl staining compared with that of wild-type mice (Fig. 2 B). MAP2 immunostaining for the dendrites of neurons in the hippocampal CA1 area of the mutant mice gave a pattern indistinguishable from that in wild-type mice (data not shown). Thus, the deficiency of ShcC did not significantly alter the hippocampal morphology in the mature brain.

\section{Enhancement of hippocampus-dependent learning and memory in ShcC mutant mice}

To investigate whether a deficiency of ShcC affects neuronal functions of the mature brain, we examined the performance of ShcC mutant mice in several behavioral paradigms. We first tested motor coordination and nociceptive response. The motility in a novel environment was measured for both horizontal (locomotion) and vertical (rearing) activities. Neither locomotion nor rearing during a $60 \mathrm{~min}$ observation period differed significantly between the wild-type mice (locomotion, 13,122.2 \pm 1197.8 counts; rearing, $70.7 \pm 13.8$ counts) and ShcC mutant mice (locomotion, 13,355.0 \pm 1405.0 counts; rearing, $81.8 \pm 14.1$ counts). Furthermore, no aberrant nociceptive responses to electric footshocks were observed in the ShcC mutant mice: the footshock threshold in the mutant mice (flinching, $0.045 \pm 0.002 \mathrm{~mA}$; vocalizing, $0.233 \pm 0.027 \mathrm{~mA}$; jumping, $0.425 \pm 0.031 \mathrm{~mA}$ ) was the same as that in wild-type mice (flinching, $0.045 \pm 0.004 \mathrm{~mA}$; vocalizing, $0.228 \pm 0.015 \mathrm{~mA}$; jumping, $0.400 \pm 0.046 \mathrm{~mA}$ ). These results indicate no apparent abnormalities in either motor or sensory neuronal systems in the ShcC mutant mice, consistent with previous observations (Sakai et al., 2000).

We next tested spatial and nonspatial learning and memory in ShcC mutant mice using the paradigms of the Morris water maze, fear conditioning, and novel object recognition tasks. In the Morris water maze task, both the wild-type and ShcC mutant mice managed to learn the visible-platform test, but the escape latency to the platform was shorter for the mutant mice (ANOVA with repeated measures; $F_{(1,22)}=4.446 ; p=0.0010$ ) (Fig. $\left.3 A a\right)$. In the hidden-platform test, which requires the activation of the NMDA receptors in the hippocampus (Morris et al., 1982; Tsien et al., 1996), ShcC mutant mice required less time to reach the platform than wild-type mice (ANOVA with repeated measures; $F_{(1,34)}=$ $3.689 ; p=0.0034$ ) (Fig. 3Ab). Swimming speeds of the wild-type and $\mathrm{ShcC}$ mutant mice in the visible- and hidden-platform tests were essentially the same (swimming speed on the first day of the hidden-platform test; wild-type mice, $17.9 \pm 1.2 \mathrm{~cm} / \mathrm{s}$; ShcC mutant mice, $18.6 \pm 1.1 \mathrm{~cm} / \mathrm{s})$. Moreover, in the platform transfer test conducted after the hidden-platform test, the ShcC mutant mice exhibited greater preference for the trained quadrant than the wild-type mice (Fig. 3Ac).

We tested for associative memory in the contextual and cued fear conditioning tasks. The former is hippocampus dependent, whereas the latter is hippocampus independent (Phillips and LeDoux, 1992). Both types of fear conditioning task also require the activation of the NMDA receptors (Davis et al., 1987; Kim et al., 1992). The contextual and cued fear conditioning tasks were measured $24 \mathrm{~h}$ after an aversive event (footshock) using two separate sets of genotype groups. The freezing response before the footshock (preconditioning) did not differ between the wild-type and ShcC mutant mice (Fig. $3 B$ ). In the contextual fear conditioning test, the freezing response $24 \mathrm{~h}$ after the footshock in both the wild-type and ShcC mutant mice significantly increased compared with the preconditioning and pseudoconditioning groups, respectively, with the mutant mice exhibiting a much stronger response than wild-type mice (Fig. $3 B$ ). In contrast, in the cued fear conditioning test, there was no significant difference in the freezing response $24 \mathrm{~h}$ after the footshock between the wild-type mice $(62.6 \pm 5.1 \%)$ and ShcC mutant mice $(64.6 \pm 3.3 \%)$.

To examine visual recognition memory in ShcC mutant mice, we used a novel object recognition task, in which the activation of the NMDA receptors in the hippocampus is essential for the formation of recognition memory (Rampon et al., 2000). We used a 5 min training protocol to assess the enhancement of learning and memory. There was no difference in exploratory preference during the training between the wild-type and ShcC mutant mice (Fig. 3C), indicating that the two groups essentially had the same levels of curiosity and/or motivation to explore the two objects. 
A
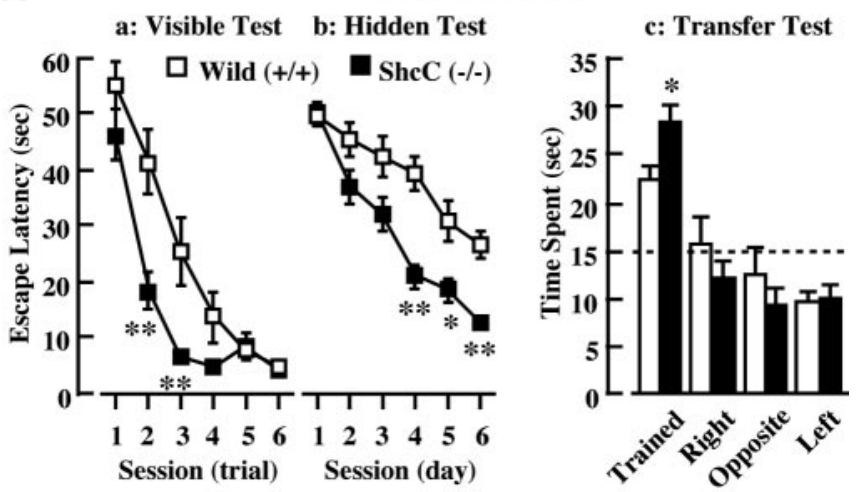

B

Fear Conditioning Task
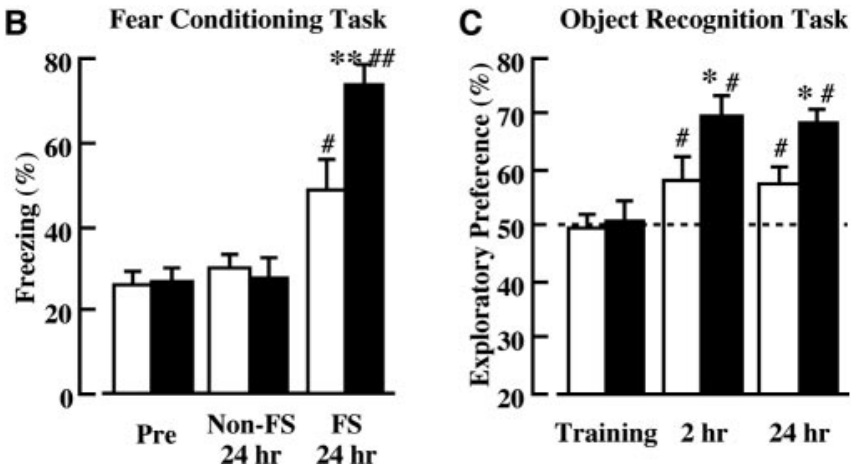

Figure 3. Hippocampus-dependent learning and memory in ShcC mutant mice. $A$, Morris water maze task. Escape latency in the visible $(\boldsymbol{a})$ - and hidden $(\boldsymbol{b})$-platform tests. $\boldsymbol{c}$, The time spent in each quadrant in the transfer test $24 \mathrm{~h}$ after the hidden-platform test. The time spent in the trained quadrant was significantly longer than that in any other quadrants in both the wild-type and ShcC mutant mice ( $p<0.05$; Student-Newman-Keuls multiple comparisons test). The dotted line represents performance by chance (15 s). $\boldsymbol{B}$, Contextual fear conditioning test. The freezing response was measured for $2 \mathrm{~min} 24 \mathrm{~h}$ after the conditioning [FS (footshock)] or pseudoconditioning (Non-FS). C, Novel object recognition test. The time spent exploring two objects was measured for 5 min during training and retention 2 or $24 \mathrm{~h}$ after the training. The dotted line represents performance by chance (50\%). Data represent mean \pm SEM $(n=$ $8-18) .{ }^{*} p<0.05$ and ${ }^{* *} p<0.01$ versus corresponding wild type $(+/+)$. ${ }^{*} p<0.05$ and $\#^{\#} p<0.01$ versus corresponding non-FS or training value in wild type $(+/+)$.

In 2 and $24 \mathrm{~h}$ retention, however, ShcC mutant mice exhibited greater preference toward the novel object than wild-type mice (Fig. 3C).

Overall, these findings in the three different paradigms suggest that hippocampus-dependent spatial and nonspatial learning and memory is enhanced in the ShcC mutant mice, and this enhancement reflects neither increased motor activity nor altered nociceptive sensitivity.

Enhancement of hippocampal LTP in ShcC mutant mice To investigate the synaptic properties in the hippocampus of ShcC mutant mice, we performed electrophysiological analyses using hippocampal slices. We used a high-speed optical recording technique in the hippocampal CA1 area by stimulating Schaffer collateral afferents from the CA3 area. With this technique, the optical signals evoked in the stratum radiatum of the CA1 area were broken down into two distinct elements, an initial spike-like component and an immediately following slow component, which could be separated by a notch in the control (Fig. $4 A a$, arrow). These components represent the presynaptic fiber volley (PSFV) and EPSP, respectively, because the spike-like component left in $\mathrm{Ca}^{2+}$-free medium (Fig. $4 A b$ ) is eliminated by tetrodotoxin (TTX; $1 \mu \mathrm{M}$ ) (Fig. 4Ad) and the slow component is
A

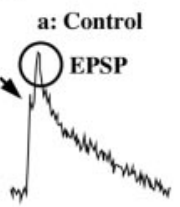

Optical Signals - HIP CA1

b: $\mathrm{Ca}^{2+}$-Free c: $\mathrm{AP5} / \mathrm{CNQX}$

d: TTX
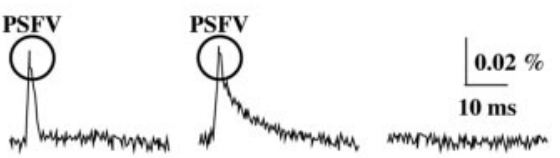

B

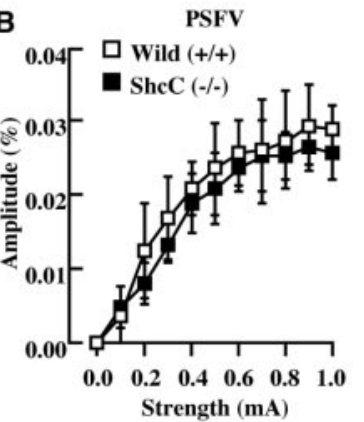

C $\quad$ EPSP
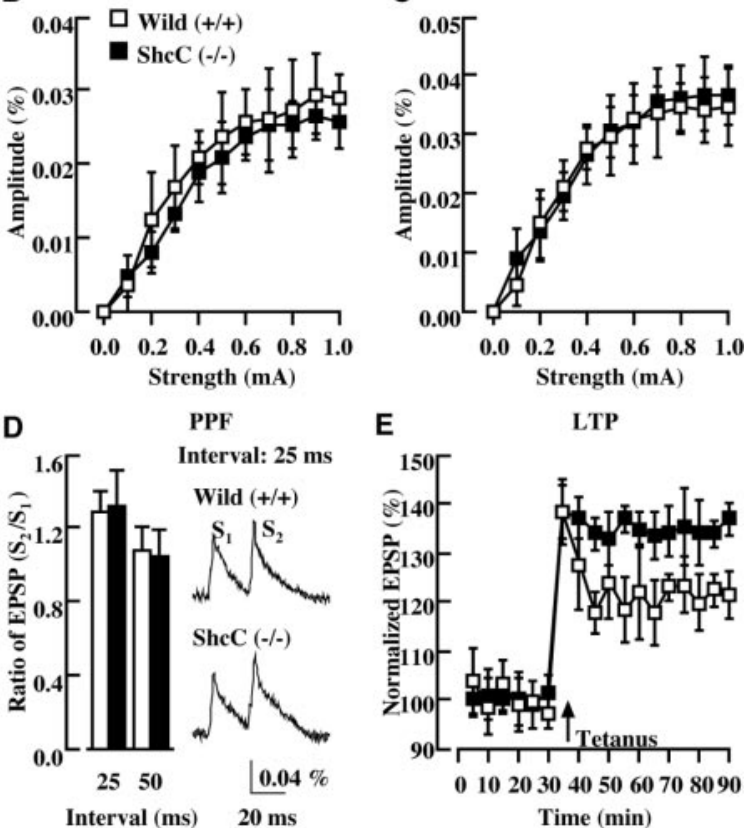

E

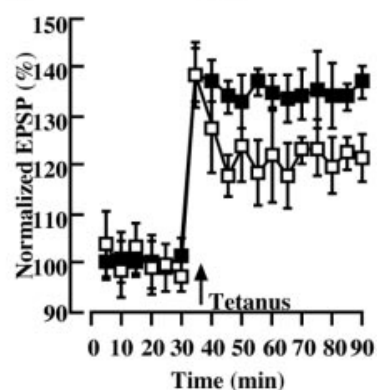

F
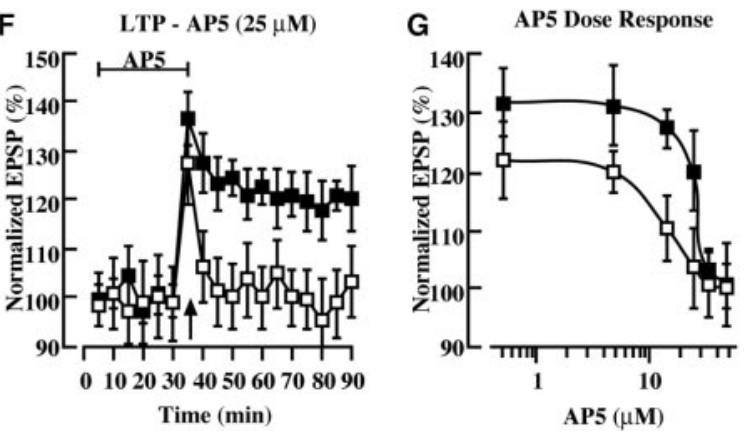

Figure 4. Hippocampal synaptic transmission and LTP in ShcC mutant mice. A, Optical signals in the stratum radiatum of the hippocampal (HIP) CA1 area. Representative traces of optical signal in response to an electrical stimulus of the Schaffer collateral fibers are shown. The control signal $(\boldsymbol{a})$ is composed of PSFV (arrow) and EPSP: the former could be separated by treatment with $\mathrm{Ca}^{2+}$-free medium (b) or AP-5 $(50 \mu \mathrm{m}) / \mathrm{CNQX}(10 \mu \mathrm{M})(\boldsymbol{c})$ and eliminated by treatment with TTX $(1 \mu \mathrm{M})(\boldsymbol{d}) . \boldsymbol{B}$, Amplitude of PSFV versus stimulus intensity. $\boldsymbol{C}$, Amplitude of EPSP versus stimulus intensity. The input-output relationship of PSFV or EPSP is plotted against stimulus intensity at the Schaffer collateral-CA1 synapses ( 5 slices from 4 wild-type mice; 5 slices from $5 \mathrm{ShcC}$ mutant mice). D, Pairedpulse facilitation (PPF). The data represent the facilitation of the second EPSP $\left(S_{2}\right)$ relative to the first $\operatorname{EPSP}\left(S_{1}\right)$. Traces are the synaptic responses evoked by paired-pulse stimulation (interval, $25 \mathrm{~ms}$ ) (4 slices from 3 wild-type mice; 4 slices from 3 ShcC mutant mice). E, Hippocampal LTP. Each point represents the mean \pm SEM EPSP normalized to the baseline EPSP, which was the mean of EPSP for 20-30 min (7 slices from 4 wild-type mice; 7 slices from 4 ShcC mutant mice). Tetanic stimulation induced LTP at 90 min in the wild-type mice (121.2 $\pm 5.0 \%)$ and ShcC mutant mice (136.8 $\pm 3.4 \%$; $p<0.05)$. $\boldsymbol{F}$, Treatment with NMDA receptor antagonist AP-5. Each point represents the normalized mean of EPSP \pm SEM in the presence of AP-5 $(25 \mu \mathrm{m})$ for $5-35$ min (4 slices from 4 wild-type mice; 6 slices from $4 \mathrm{ShcC}$ mutant mice). Tetanic stimulation with AP-5 treatment failed to induce LTP in the wild-type mice (103.5 $\pm 7.0 \%$ at $90 \mathrm{~min}$ ), and induced LTP in ShcC mutantmice (120.1 $\pm 6.7 \%$ at 90 $\min ; p<0.05)$. G, Dose- effect of AP-5 on LTP expression. Each point represents the normalized mean \pm SEM EPSP at 60 min after the tetanic stimulation in the presence of different concentrations of AP-5 (4 slices from 4 wild-type mice; 6 slices from $4 \mathrm{ShcC}$ mutant mice) ( $\mathrm{EC}_{50}$; wild-type mice, 15.2 $\mu \mathrm{m}$; Shc (mutant mice, $26.6 \mu \mathrm{m})$. 
blocked by D-2-amino-5-phosphonovaleric acid (AP-5; $50 \mu \mathrm{M}) /$ 6-cyano-7-nitroquinoxaline-2,3-dione (CNQX; $10 \mu \mathrm{M})$, competitive NMDA and AMPA receptor antagonists (Fig. 4Ac).

Initial experiments were designed to examine the input-output relationship of synaptic transmission by measuring two distinct components for a range of stimulus intensities. The amplitude of PSFV in the wild-type and ShcC mutant mice was almost the same (Fig. $4 B$ ), indicating that presynaptic properties were not altered in the mutant mice. There was no difference in the amplitude of EPSP between the wild-type and ShcC mutant mice (Fig. 4C), indicating that basal synaptic transmission remains normal in the mutant mice. Similarly, paired-pulse facilitation, which is a short-term enhancement of synaptic efficacy in response to a closely spaced second stimulus and reflects the probability of neurotransmitter release from afferent neurons, differed little between the wild-type and ShcC mutant mice (Fig. $4 D)$. These results suggest that synaptic transmission does not deteriorate at the hippocampal Schaffer collateral-CA1 synapses in the ShcC mutant mice.

The LTP in the hippocampal CA1 area, a typical form of synaptic plasticity, is known to involve the activation of the NMDA receptors in its induction. We next examined the synaptic plasticity at hippocampal CA1 synapses using a high-frequency conditioning, tetanic stimulation $(100 \mathrm{~Hz} ; 1 \mathrm{~s})$ to induce LTP. There was a marked difference in the expression of hippocampal LTP between the wild-type and ShcC mutant mice (Fig. $4 E$ ). The early phase of LTP in ShcC mutant mice was consistently enhanced during observation up to $60 \mathrm{~min}$ after the tetanic stimulation (wild-type mice, $121.2 \pm 5.0 \%$; ShcC mutant mice, $136.8 \pm$ $3.4 \%$; $p<0.05$ ) (Fig. $4 E$, EPSP at $90 \mathrm{~min}$ ). The treatment with AP-5 $(25 \mu \mathrm{M})$ before the tetanic stimulation in wild-type mice completely blocked the expression of LTP, whereas that in ShcC mutant mice induced LTP (EPSP at $90 \mathrm{~min}$ ) (wild-type mice, $103.5 \pm 7.0 \%$; ShcC mutant mice, $120.1 \pm 6.7 \%$; $p<0.05$ ) (Fig. $4 F$ ). As shown in Figure $4 G$, AP-5 dose-dependently inhibited the expression of LTP in both the wild-type and ShcC mutant mice, but with different $\mathrm{EC}_{50}$ values of AP-5 between the two groups (wild-type mice, $15.2 \mu \mathrm{M}$; ShcC mutant mice, $26.6 \mu \mathrm{M}$ ). These results suggest that the enhancement of hippocampal LTP in ShcC mutant mice would arise from the functional alteration of postsynaptic NMDA receptors in the hippocampal CA1 area, because presynaptic function is normal in this area.

Increased phosphorylation of the NMDA receptors in the hippocampus of ShcC mutant mice

The NMDA receptors are formed by NR1 (GluR $\zeta 1$ ) and NR2A to NR2D (GluR $\epsilon 1$ to GluR $\epsilon 4)$ subunits (Hollmann and Heinemann, 1994; Nakanishi and Masu, 1994), and their activity is modulated by either the subunit composition of the receptor (Kutsuwada et al., 1992; Monyer et al., 1994) or phosphorylation of the subunits (Wang and Salter, 1994; Yu et al., 1997). To investigate NMDA receptor activity in the hippocampus of ShcC mutant mice, we examined the expression and phosphorylation levels of the receptor subunits. There was no difference in the expression level of the NR2A, NR2B, or NR1 subunit in the hippocampus between the wild-type and ShcC mutant mice (Fig. $5 A$ ). The expression level of PSD95, which regulates the signaling by the NMDA receptors, was the same in ShcC mutant mice as in wild-type mice (Fig. 5A). However, the tyrosine phosphorylation level of NR2A or NR2B in ShcC mutant mice showed a significant increase compared with that in wild-type mice (Fig. 5A). These findings suggest that the basal function of the NMDA receptors in
A

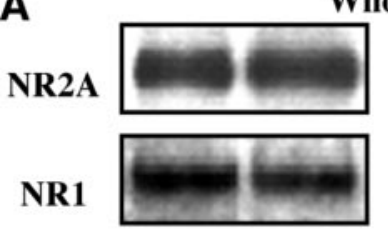

Whole Lysate - HIP

\section{IP: NR2A}
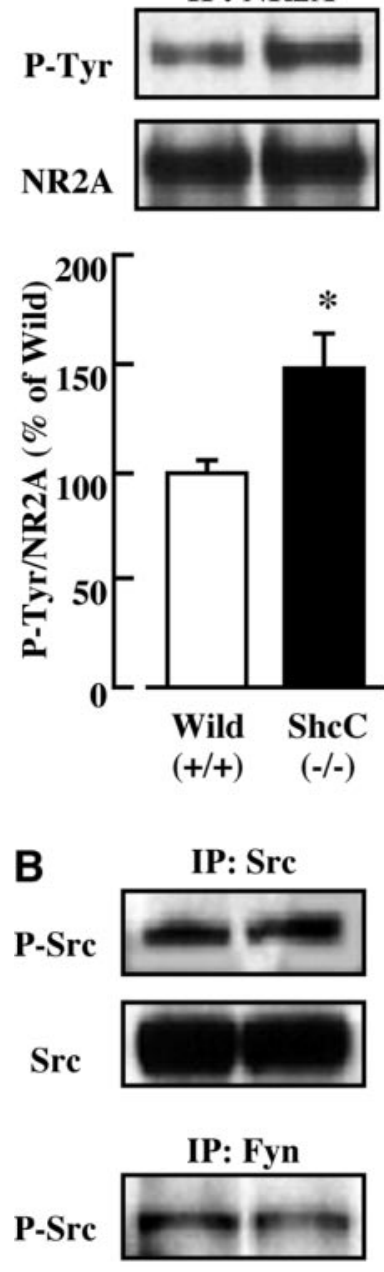

Fyn

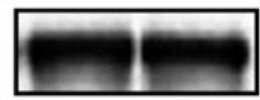

Wild ShcC

$(+/+) \quad(-/-)$

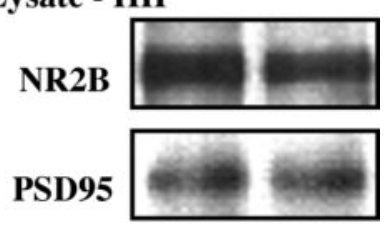

IP: NR2B
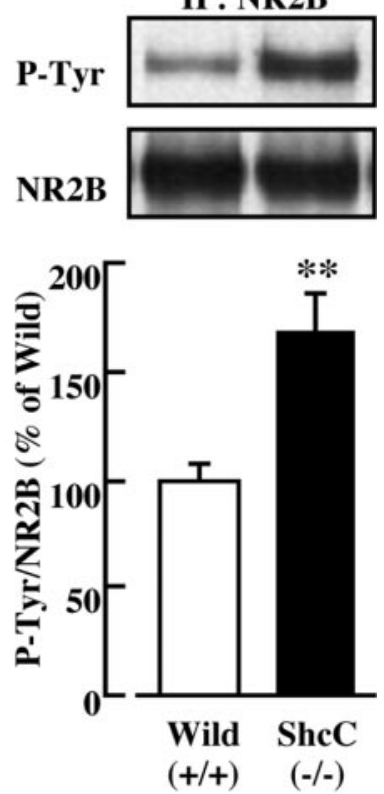

C

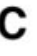

Src Family Kinase Activity

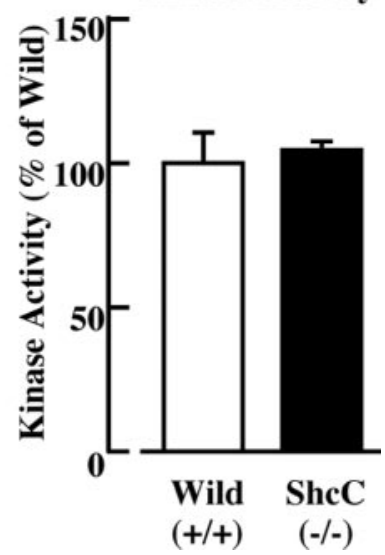

Figure 5. Phosphorylation of the NMDA receptors and kinase activity of the Src family in the hippocampus of ShcC mutant mice. $A$, Expression and tyrosine phosphorylation of the NR2A and NR2B subunits. The whole lysates of the hippocampus (HIP) were immunoblotted with anti-NR2A, -NR2B, -NR1, or -PSD95 antibody. To dissociate the NMDA receptor complex, hippocampal lysates with a modified lysis buffer were boiled for $5 \mathrm{~min}$. The immunoprecipitates (IP) obtained with antiNR2A or -NR2B antibody were immunoblotted with anti-phosphotyrosine (P-Tyr) antibody. B, Tyrosine phosphorylation at the activation site of Src and Fyn. The immunoprecipitates prepared with anti-Src or -Fyn antibody were immunoblotted with anti-phospho-Src (P-Src) family antibody. C, Kinase activity of the Src family in vitro. The immunoprecipitates obtained with anti-Src family antibody were subjected to an in vitro Src kinase assay. Data represent mean $\pm \operatorname{SEM}(n=4)$. ${ }^{*} p<0.05$ and $^{* *} p<0.01$ versus corresponding wild type $(+/+)$.

the hippocampus of ShcC mutant mice is enhanced by the hyperphosphorylation at tyrosine residues of the receptor subunits.

Because the tyrosine phosphorylation of subunits NR2A and $\mathrm{NR} 2 \mathrm{~B}$ of the NMDA receptors is known to be modulated by the 
Src family of cytoplasmic tyrosine kinases, including Src and Fyn (Hisatsune et al., 1999; Nakazawa et al., 2001), we tested the kinase activity of this family in the hippocampus of ShcC mutant mice. However, there was no notable difference in the tyrosine phosphorylation level at the activation site of Src or Fyn between the wild-type and ShcC mutant mice (Fig. 5B). Moreover, the kinase activity of the Src family in the mutant mice was similar to that in wild-type mice (Fig. $5 C$ ). These results indicate that increased tyrosine phosphorylation of the NMDA receptors in the ShcC mutant mice is not attributable to the activation of Src and Fyn.

Interaction of ShcC/N-Shc with the NMDA receptors and the Src family in the hippocampus

To clarify the regulatory mechanism of ShcC in NMDA receptor function involved in hippocampal synaptic plasticity, we investigated whether ShcC interacts with the NMDA receptors and the Src family. In an immunoprecipitation assay using lysates prepared from the hippocampus of wild-type mice, the NR1 or NR2B subunit of the NMDA receptors coprecipitated greatly with ShcC compared with other Shc family members (Fig. 6A). Similarly, Src (or Fyn) also interacted with ShcC (Fig. 6A). To further test whether these interactions would be affected by the activation of excitatory synaptic transmission, we examined the interaction between ShcC and the NR2B subunit or the Src family under conditions of glutamate stimulation in hippocampal slices from wild-type mice. After a 5 min stimulation with glutamate $(100 \mu \mathrm{M})$ in the presence of glycine $(10 \mu \mathrm{M})$ and spermidine ( $1 \mathrm{mM})$, both endogenous coactivators for the NMDA receptors, the amount of NR2B subunit coimmunoprecipitated with ShcC increased significantly (Fig. 6B). In the same conditions, the interaction of Src (or Fyn) with ShcC also increased significantly (Fig. $6 B$ ). These findings indicate that ShcC binds to the NMDA receptors and also associates with Src and/or Fyn in the mature hippocampus, and the formation of this ternary complex is stimulated by the activation of the excitatory glutamatergic neuronal system.

\section{Discussion}

In the present study, we demonstrated that the phosphotyrosine adapter protein ShcC/N-Shc is implicated in the modulation of hippocampal synaptic plasticity. However, as described in Introduction, hippocampal LTP may not rely on the Shc-mediated TrkB-Ras/MAPK signaling (Korte et al., 2000; Minichiello et al., 2002). Rather than the Shc/Ras/MAPK pathway, the PLC $\gamma /$ IP3/ CaMKIV pathway may be more relevant to the modulation of hippocampal LTP immediately downstream of the TrkB receptor (Minichiello et al., 2002). Thus, our results were unexpected, and we were interested in the novel role of ShcC to modulate the hippocampal LTP underlying learning and memory. We therefore estimate that the role of ShcC in hippocampal synaptic plasticity is independent of the Ras/MAPK pathway from the TrkB receptor and is critical to the modulation of NMDA receptor function, based on the attenuated effect of an NMDA receptor antagonist on LTP expression and the increased tyrosine phosphorylation of the NMDA receptors in the hippocampus of ShcC mutant mice.

\section{Role of ShcC/N-Shc in hippocampal synaptic plasticity via interaction with the NMDA receptor}

We have shown here that ShcC specifically interacted with the NR2B subunit of the NMDA receptors and Src (or Fyn) of tyrosine kinases in the hippocampus, and these interactions were

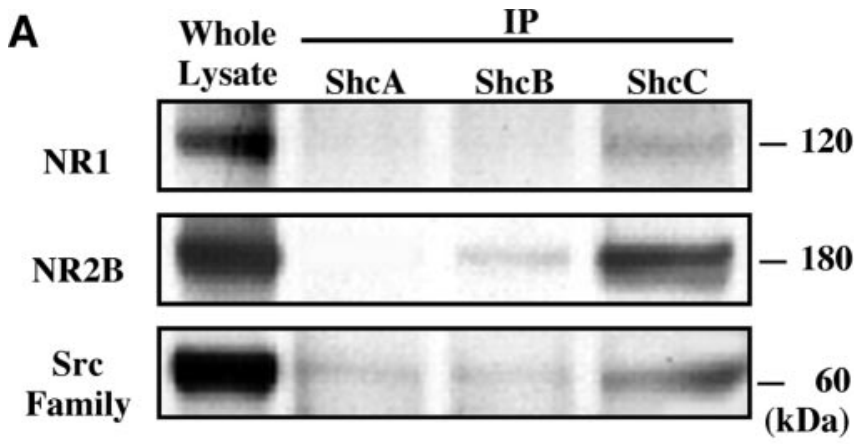

B
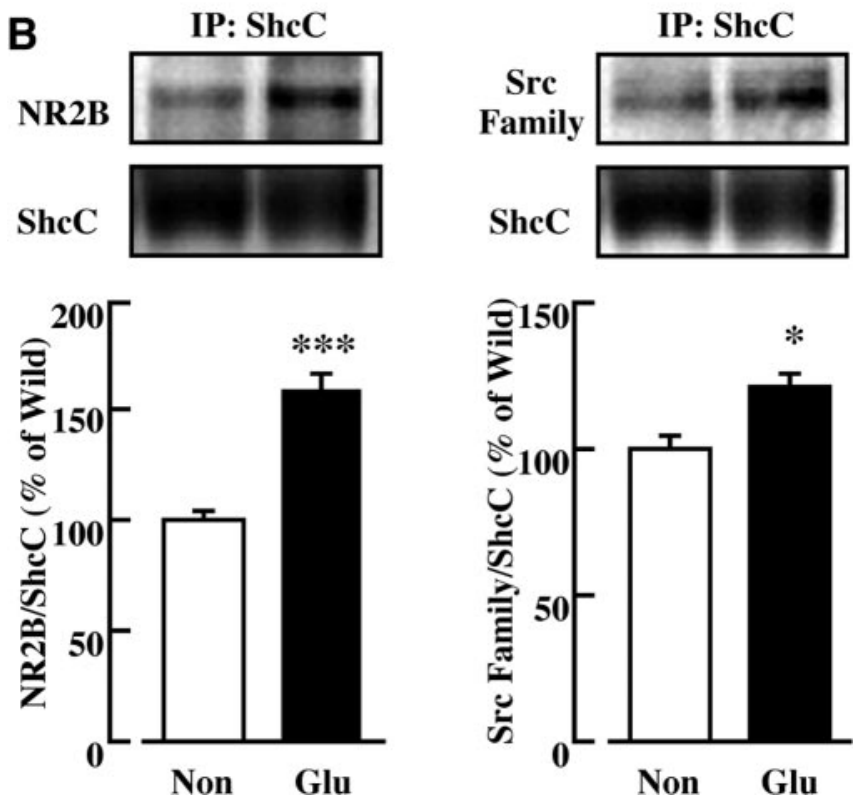

Figure 6. Interaction of ShcC with the NMDA receptors and the Src family in the hippocampus. $\boldsymbol{A}$, Coimmunoprecipitation with Shc family members in the hippocampus. The immunoprecipitates (IP) obtained with antibodies for ShCA, ShcB, or ShcC were immunoblotted with anti-NR1, -NR2B, or -Src family antibody. $B$, Coimmunoprecipitation with ShcC in the hippocampus after glutamate (Glu) stimulation. Hippocampal slices were treated with glutamate $(100 \mu \mathrm{m}) /$ glycine $(10 \mu \mathrm{m}) /$ spermidine $(1 \mathrm{~mm})$ for $5 \mathrm{~min}$. The immunoprecipitates (IP) prepared with anti-ShcC antibody were immunoblotted with anti-NR2B or -Src family antibody. Data represent mean \pm SEM $(n=4) .{ }^{*} p<0.05$ and $^{* * *} p<0.001$ versus corresponding wild type $(+/+)$.

enhanced by glutamate stimulation. The NR2B subunit is phosphorylated at several tyrosine residues by Src and Fyn (Hisatsune et al., 1999; Nakazawa et al., 2001), and the phosphorylation levels are upregulated by tetanic stimulation to induce hippocampal LTP (Rosenblum et al., 1996; Rostas et al., 1996). Thus, it is plausible that ShcC affects NMDA receptor function by binding to the receptor subunit via its phosphotyrosine binding property in an activity-dependent manner. Therefore, ShcC would regulate the receptor activation in the hippocampal LTP through Src family kinase-mediated tyrosine phosphorylation.

The elevated tyrosine phosphorylation levels of NMDA receptor subunits and normal kinase activity levels of the Src family in the hippocampus of ShcC mutant mice suggest that ShcC is implicated in the dephosphorylation of the receptor subunits. If the phosphorylation of the NMDA receptors is downregulated in the presence of ShcC, a potential role of ShcC could be to recruit a certain protein tyrosine phosphatase to the receptor multicomplex or to activate directly or indirectly a phosphatase for phosphotyrosine residues on the receptor subunits. Thus, ShcC binds 
the phosphorylated NMDA receptor subunits and also may modulate the dephosphorylation status of the receptor subunits. Alternatively, if the NMDA receptor phosphorylation is upregulated in the presence of $\mathrm{ShcC}$, the interaction of $\mathrm{ShcC}$ with a phosphorylated tyrosine of the receptor subunits may mask other tyrosine residues on the subunits from additional phosphorylation by the Src family. Otherwise, ShcC may inhibit activation of an unknown tyrosine kinase for the receptor subunits. Therefore, ShcC would contribute to the interaction between Src-like tyrosine kinase and a tyrosine phosphatase around the NMDA receptor multicomplex, to modulate the hippocampal synaptic plasticity via the receptor activation.

In general, synaptic plasticity is considered a leading candidate for a cellular mechanism of learning and memory (Bliss and Collingridge, 1993; Malenka and Nicoll, 1999), and a good correlation between NMDA receptor-dependent LTP and spatial learning and memory has been demonstrated (Tsien et al., 1996; Tang et al., 1999). Therefore, the superior hippocampusdependent learning and memory in ShcC mutant mice would be primarily caused by the enhanced NMDA receptor-dependent hippocampal LTP. As evidence to support the above estimation, the difference in the performance of ShcC mutant mice between the contextual and cued fear conditioning tasks should be mentioned. The contextual associative memory is hippocampus dependent, whereas the cued associative memory is hippocampus independent (Phillips and LeDoux, 1992). Both associative memories also depend on the amygdala (Lavond et al., 1993) and NMDA receptor activation (Davis et al., 1987; Kim et al., 1992). Thus, the enhancement of only the former in ShcC mutant mice suggests the specific activation of the NMDA receptors in the hippocampus of the mutant mice.

However, the enhancement of behavioral performance in ShcC mutant mice was observed not only in the hidden-platform test of the Morris water maze task that depends on the hippocampus but also in the visible-platform test that is not necessarily hippocampus dependent. Thus, the performance of ShcC mutant mice in the present behavioral tasks may not be affected by only a specific improvement of hippocampus-dependent learning and memory. There are several explanations for the better performance of ShcC mutant mice in the latter test (e.g., the alteration of motility, emotionality, and visual acuity). Although there was at least no difference in the motility, especially swimming ability, of ShcC mutant mice, emotionality such as motivation to escape from water may be affected by alterations of NMDA receptor function in the hippocampus, because the alterations are known to influence emotion-associated neuronal circuits in other regions of the brain (e.g., the dopaminergic and serotonergic neuronal systems in the cerebral cortex and striatum) (Mohn et al., 1999; Miyamoto et al., 2001). Currently, there is no evidence that ShcC is involved in emotionality and those neuronal systems. However, because ShcC is expressed in the retinal ganglion cell during perinatal development (Nakazawa et al., 2002), a loss of ShcC may have some influence on the performance of visual acuity. Therefore, there is a need to investigate the emotional and visual performance in $\mathrm{ShcC}$ mutant mice.

\section{Upstream and downstream signaling of the ShcC/N-Shc associated with hippocampal synaptic plasticity}

We discussed above that $\mathrm{ShcC}$ plays a role in the modulation of hippocampal synaptic plasticity via interaction with the postsynaptic NMDA receptors but not with the BDNF-stimulated TrkB receptors. This idea is consistent with the findings that ShcC accumulates in the PSD (Suzuki et al., 1999) and BDNF is re- quired for presynaptic but not postsynaptic modulation of LTP in the hippocampal CA3-CA1 synapses (Xu et al., 2000; Zakharenko et al., 2003). However, it remains possible that $\mathrm{ShcC}$ is involved in TrkB-mediated hippocampal synaptic plasticity at the postsynapses, because BDNF was taken up by postsynaptic neurons in an activity-dependent manner (Kohara et al., 2001). Thus, the enhanced hippocampal LTP in ShcC mutant mice may be caused in part by alterations of postsynaptic TrkB receptor signaling, for example, through activation of the PLC $\gamma$-mediated TrkB-IP3/CaMKIV pathway that is proposed to be relevant to hippocampal LTP (Minichiello et al., 2002). More studies are needed to clarify the signaling capabilities of the BDNFstimulated TrkB receptors in the absence of ShcC and the signaling ability of ShcC as a go-between adapter protein for the TrkB and NMDA receptors, because NMDA receptor activation is frequently associated with TrkB-mediated hippocampal LTP (Suen et al., 1997; Levine et al., 1998). In addition, it is essential to investigate directly the NMDA receptor synaptic responses in ShcC mutant mice, because our findings showed only differences in the contribution of NMDA receptor to hippocampal LTP in the mutant mice.

Similarly to ShcC mutant mice, mice lacking H-Ras showed enhanced hippocampal LTP and tyrosine phosphorylation of the NMDA receptors (Manabe et al., 2000). These enhancements explained why the deficiency of H-Ras increased Src kinase activity and subsequently potentiated the receptor function associated with hippocampal LTP (Thornton et al., 2003). These findings might suggest that ShcC modulates NMDA receptor function for hippocampal LTP via inhibition of Src kinase activity through the Ras family, including H-Ras, because ShcC transmits BDNFstimulated TrkB receptor signaling to the Ras/MAPK pathway (Nakamura et al., 1998; Liu and Meakin, 2002). In this study, however, Src and Fyn kinase activity were unaffected in the hippocampus of ShcC mutant mice, which was distinct from the case of H-Ras mutant mice.

Hippocampal synaptic modulation by ShcC may also involve other molecules. A novel $250 \mathrm{kDa}$ Rho-GTPase activating protein (GAP) Grit (Nakamura et al., 2002), also termed RICS (Rho GAP involved in the $\beta$-catenin-N-cadherin and NMDA receptor signaling) (Okabe et al., 2003) or p250GAP (Nakazawa et al., 2003), is suggested to be involved in modulation of NMDA receptor signaling. Grit was identified originally as a binding partner of ShcC and is involved in neurotrophin-dependent neurite outgrowth via the specific modulation of cytoskeletal actin dynamics (Nakamura et al., 2002). Actin dynamics in dendritic spines have been implicated in hippocampal LTP (Engert and Bonhoeffer, 1999; Matus, 2000). Grit interacted with the NR2B subunit of the NMDA receptors, and this interaction was modulated by the receptor activation (Nakazawa et al., 2003). These findings suggest that Grit regulates the NMDA receptor-dependent actin reorganization in dendritic spines. Thus, the absence of ShcC may also influence the localization of Grit and further affect the postsynaptic remodeling of the cytoskeleton underneath the NMDA receptors, which is associated with hippocampal LTP underlying learning and memory (Milner et al., 1998). It could be that multiple molecules are needed to regulate synaptic function for hippocampal LTP (Sanes and Lichtman, 1999; Inoue and Okabe, 2003); however, ShcC would be a modulatory component of these molecules at the hippocampal synapses.

In summary, our observations revealed that the enhancement of hippocampal LTP in ShcC mutant mice is primarily attributable to an alteration of NMDA receptor function rather than an effect on the TrkB-Shc site. The current study established that the 
neural-specific phosphotyrosine adapter protein $\mathrm{ShcC} / \mathrm{N}-\mathrm{Shc}$ is a modulator of hippocampal synaptic plasticity underlying learning and memory.

\section{References}

Adams JP, Sweatt JD (2002) Molecular psychology: roles for the ERK MAP kinase cascade in memory. Annu Rev Pharmacol Toxicol 42:135-163.

Bliss TV, Collingridge GL (1993) A synaptic model of memory: long-term potentiation in the hippocampus. Nature 361:31-39.

Cattaneo E, Pelicci PG (1998) Emerging roles for SH2/PTB-containing Shc adaptor proteins in the developing mammalian brain. Trends Neurosci 21:476-481.

Davis M, Hitchcock J, Rosen JB (1987) Anxiety and the amygdala: pharmacological and anatomical analysis of the fear-potentiated startle paradigm. In: The psychology of learning and motivation (Bower GH, ed), pp 263305. New York: Academic.

Engert F, Bonhoeffer T (1999) Dendritic spine changes associated with hippocampal long-term synaptic plasticity. Nature 399:66-70.

Hisatsune C, Umemori H, Mishina M, Yamamoto T (1999) Phosphorylationdependent interaction of the $N$-methyl-D-aspartate receptor $\epsilon 2$ subunit with phosphatidylinositol 3-kinase. Genes Cells 4:657-666.

Hollmann M, Heinemann S (1994) Cloned glutamate receptors. Annu Rev Neurosci 17:31-108.

Inoue A, Okabe S (2003) The dynamic organization of postsynaptic proteins: translocating molecules regulate synaptic function. Curr Opin Neurobiol 13:332-340.

Kaplan DR, Miller FD (2000) Neurotrophin signal transduction in the nervous system. Curr Opin Neurobiol 10:381-391.

Kim JJ, Fanselow MS, DeCola JP, Landeira-Fernandez J (1992) Selective impairment of long-term but not short-term conditional fear by the $N$-methyl-D-aspartate antagonist APV. Behav Neurosci 106:591-596.

Kohara K, Kitamura A, Morishima M, Tsumoto T (2001) Activitydependent transfer of brain-derived neurotrophic factor to postsynaptic neurons. Science 291:2419-2423.

Kojima T, Yoshikawa Y, Takada S, Sato M, Nakamura T, Takahashi N, Copeland NG, Gilbert DJ, Jenkins NA, Mori N (2001) Genomic organization of the Shc-related phosphotyrosine adapters and characterization of the full-length Sck/ShcB: specific association of p68-Sck/ShcB with pp135. Biochem Biophys Res Commun 284:1039-1047.

Korte M, Minichiello L, Klein R, Bonhoeffer T (2000) Shc-binding site in the TrkB receptor is not required for hippocampal long-term potentiation. Neuropharmacology 39:717-724.

Kutsuwada T, Kashiwabuchi N, Mori H, Sakimura K, Kushiya E, Araki K, Meguro H, Masaki H, Kumanishi T, Arakawa M, Mishina M (1992) Molecular diversity of the NMDA receptor channel. Nature 358:36-41.

Lavond DG, Kim JJ, Thompson RF (1993) Mammalian brain substrates of aversive classical conditioning. Annu Rev Psychol 44:317-342.

Levine ES, Crozier RA, Black IB, Plummer MR (1998) Brain-derived neurotrophic factor modulates hippocampal synaptic transmission by increasing $N$-methyl-D-aspartic acid receptor activity. Proc Natl Acad Sci USA 95:10235-10239.

Liu HY, Meakin SO (2002) ShcB and ShcC activation by the Trk family of receptor tyrosine kinases. J Biol Chem 277:26046-26056.

Lu B (2003) BDNF and activity-dependent synaptic modulation. Learn Mem 10:86-98.

Malenka RC, Nicoll RA (1999) Long-term potentiation-a decade of progress? Science 285:1870-1874.

Manabe T, Aiba A, Yamada A, Ichise T, Sakagami H, Kondo H, Katsuki M (2000) Regulation of long-term potentiation by H-Ras through NMDA receptor phosphorylation. J Neurosci 20:2504-2511.

Matus A (2000) Actin-based plasticity in dendritic spines. Science 290:754-758.

Milner B, Squire LR, Kandel ER (1998) Cognitive neuroscience and the study of memory. Neuron 20:445-468.

Minichiello L, Calella AM, Medina DL, Bonhoeffer T, Klein R, Korte M (2002) Mechanism of TrkB-mediated hippocampal long-term potentiation. Neuron 36:121-137.

Miyamoto Y, Yamada K, Noda Y, Mori H, Mishina M, Nabeshima T (2001) Hyperfunction of dopaminergic and serotonergic neuronal systems in mice lacking the NMDA receptor epsilon1 subunit. J Neurosci 21:750-757.

Mohn AR, Gainetdinov RR, Caron MG, Koller BH (1999) Mice with re- duced NMDA receptor expression display behaviors related to schizophrenia. Cell 98:427-436.

Monyer H, Burnashev N, Laurie DJ, Sakmann B, Seeburg PH (1994) Developmental and regional expression in the rat brain and functional properties of four NMDA receptors. Neuron 12:529-540.

Morris RG, Garrud P, Rawlins JN, O’Keefe J (1982) Place navigation impaired in rats with hippocampal lesions. Nature 24:681-683.

Nakamura T, Muraoka S, Sanokawa R, Mori N (1998) N-Shc and Sck, two neuronally expressed Shc adapter homologs. Their differential regional expression in the brain and roles in neurotrophin and Src signaling. J Biol Chem 273:6960-6967.

Nakamura T, Komiya M, Sone K, Hirose E, Gotoh N, Morii H, Ohta Y, Mori N (2002) Grit, a GTPase-activating protein for the Rho family, regulates neurite extension through association with the TrkA receptor and N-Shc and CrkL/Crk adapter molecules. Mol Cell Biol 22:8721-8734.

Nakanishi S, Masu M (1994) Molecular diversity and functions of glutamate receptors. Annu Rev Biophys Biomol Struct 23:319-348.

Nakazawa T, Komai S, Tezuka T, Hisatsune C, Umemori H, Semba K, Mishina M, Manabe T, Yamamoto T (2001) Characterization of Fynmediated tyrosine phosphorylation sites on GluR $\epsilon 2$ (NR2B) subunit of the $N$-methyl-D-aspartate receptor. J Biol Chem 276:693-699.

Nakazawa T, Nakano I, Sato M, Nakamura T, Tamai M, Mori N (2002) Comparative expression profiles of Trk receptors and Shc-related phosphotyrosine adapters during retinal development: potential roles of $\mathrm{N}$ Shc/ShcC in brain-derived neurotrophic factor signal transduction and modulation. J Neurosci Res 68:668-680.

Nakazawa T, Watabe AM, Tezuka T, Yoshida Y, Yokoyama K, Umemori H Inoue A, Okabe S, Manabe T, Yamamoto T (2003) p250GAP, a novel brain-enriched GTPase-activating protein for Rho family GTPases, is involved in the $N$-methyl-D-aspartate receptor signaling. Mol Biol Cell 14:2921-2934.

Ohno M, Frankland PW, Chen AP, Costa RM, Silva AJ (2001) Inducible, pharmacogenetic approaches to the study of learning and memory. Nat Neurosci 4:1238-1243.

Okabe T, Nakamura T, Nishimura YN, Kohu K, Ohwada S, Morishita Y, Akiyama T (2003) RICS, a novel GTPase-activating protein for Cdc42 and Racl, is involved in the $\beta$-catenin- $\mathrm{N}$-cadherin and $N$-methyl-Daspartate receptor signaling. J Biol Chem 278:9920-9927.

Patapoutian A, Reichardt LF (2001) Trk receptors: mediators of neurotrophin action. Curr Opin Neurobiol 11:272-280.

Phillips RG, LeDoux JE (1992) Differential contribution of amygdala and hippocampus to cued and contextual fear conditioning. Behav Neurosci 106:274-285.

Poo MM (2001) Neurotrophins as synaptic modulators. Nat Rev Neurosci 2:24-32.

Rampon C, Tang YP, Goodhouse J, Shimizu E, Kyin M, Tsien JZ (2000) Enrichment induces structural changes and recovery from nonspatial memory deficits in CAl NMDAR1-knockout mice. Nat Neurosci 3:238-244.

Ravichandran KS (2001) Signaling via Shc family adapter proteins. Oncogene 20:6322-6330.

Rosenblum K, Dudai Y, Richter-Levin G (1996) Long-term potentiation increases tyrosine phosphorylation of the $N$-methyl-D-aspartate receptor subunit $2 \mathrm{~B}$ in rat dentate gyrus in vivo. Proc Natl Acad Sci USA 93:10457-10460.

Rostas JA, Brent VA, Voss K, Errington ML, Bliss TV, Gurd JW (1996) Enhanced tyrosine phosphorylation of the $2 \mathrm{~B}$ subunit of the $N$-methyl-Daspartate receptor in long-term potentiation. Proc Natl Acad Sci USA 93:10452-10456.

Sakai R, Henderson JT, O’Bryan JP, Elia AJ, Saxton TM, Pawson T (2000) The mammalian ShcB and ShcC phosphotyrosine docking proteins function in the maturation of sensory and sympathetic neurons. Neuron 28:819-833.

Sanes JR, Lichtman JW (1999) Can molecules explain long-term potentiation? Nat Neurosci 2:597-604.

Silva AJ (2003) Molecular and cellular cognitive studies of the role of synaptic plasticity in memory. J Neurobiol 54:224-237.

Suen PC, Wu K, Levine ES, Mount HT, Xu JL, Lin SY, Black IB (1997) Brain-derived neurotrophic factor rapidly enhances phosphorylation of the postsynaptic $N$-methyl-D-aspartate receptor subunit 1 . Proc Natl Acad Sci USA 94:8191-8195.

Suzuki T, Mitake S, Murata S (1999) Presence of up-stream and down- 
stream components of a mitogen-activated protein kinase pathway in the PSD of the rat forebrain. Brain Res 840:36-44.

Tang YP, Shimizu E, Dube GR, Rampon C, Kerchner GA, Zhuo M, Liu G, Tsien JZ (1999) Genetic enhancement of learning and memory in mice. Nature 401:63-69.

Thornton C, Yaka R, Dinh S, Ron D (2003) H-Ras modulates NMDA receptor function via inhibition of Src tyrosine kinase activity. J Biol Chem 278:23823-23829.

Tsien JZ, Huerta PT, Tonegawa S (1996) The essential role of hippocampal CA1 NMDA receptor-dependent synaptic plasticity in spatial memory. Cell 87:1327-1338.

Wang YT, Salter MW (1994) Regulation of NMDA receptors by tyrosine kinases and phosphatases. Nature 369:233-235.

Xu B, Gottschalk W, Chow A, Wilson RI, Schnell E, Zang K, Wang D, Nicoll RA, Lu B, Reichardt LF (2000) The role of brain-derived neurotrophic factor receptors in the mature hippocampus: modulation of long-term potentiation through a presynaptic mechanism involving TrkB. J Neurosci 20:6888-6897.
Ying SW, Futter M, Rosenblum K, Webber MJ, Hunt SP, Bliss TV, Bramham CR (2002) Brain-derived neurotrophic factor induces long-term potentiation in intact adult hippocampus: requirement for ERK activation coupled to CREB and upregulation of Arc synthesis. J Neurosci 22:1532-1540.

Yu XM, Askalan R, Keil II GJ, Salter MW (1997) NMDA channel regulation by channel-associated protein tyrosine kinase Src. Science 275:674-678.

Zakharenko SS, Patterson SL, Dragatsis I, Zeitlin SO, Siegelbaum SA, Kandel ER, Morozov A (2003) Presynaptic BDNF required for a presynaptic but not postsynaptic component of LTP at hippocampal CA1-CA3 synapses. Neuron 39:975-990.

Zamanillo D, Sprengel R, Hvalby O, Jensen V, Burnashev N, Rozov A, Kaiser KM, Koster HJ, Borchardt T, Worley P, Lubke J, Frotscher M, Kelly PH, Sommer B, Andersen P, Seeburg PH, Sakmann B (1999) Importance of AMPA receptors for hippocampal synaptic plasticity but not for spatial learning. Science 284:1805-1811. 